\title{
Young Caregivers in the End-of-Life Setting: A Population-Based Profile of an Emerging Group
}

\author{
Catherine Mary Burns, B.A., BSWSA, MPhil, Ph.D.,' Thomas William LeBlanc, M.D., M.A., ${ }^{2}$ \\ Amy Abernethy, M.D., ${ }^{2}$ and David Currow, M.P.H., FRACP ${ }^{1}$
}

\begin{abstract}
Purpose: Little is known about young caregivers of people with advanced life-limiting illness. Better understanding of the needs and characteristics of these young caregivers can inform development of palliative care and other support services.

Methods: A population-based analysis of caregivers was performed from piloted questions included in the 20012007 face-to-face annual health surveys of 23,706 South Australians on the death of a loved one, caregiving provided, and characteristics of the deceased individual and caregiver. The survey was representative of the population by age, gender, and region of residence.

Findings: Most active care was provided by older, close family members, but large numbers of young people (ages 15-29) also provided assistance to individuals with advanced life-limiting illness. They comprised $14.4 \%$ of those undertaking "hands-on" care on a daily or intermittent basis, whom we grouped together as active caregivers. Almost as many young males as females participate in active caregiving (men represent $46 \%$ ); most provide care while being employed, including 38\% who work full-time. Over half of those engaged in hands-on care indicated the experience to be worse or much worse than expected, with young people more frequently reporting dissatisfaction thereof. Young caregivers also exhibited an increased perception of the need for assistance with grief.

Conclusion: Young people can be integral to end-of-life care, and represent a significant cohort of active caregivers with unique needs and experiences. They may have a more negative experience as caregivers, and increased needs for grief counseling services compared to other age cohorts of caregivers.
\end{abstract}

\section{Introduction}

$\mathrm{C}$ LINICAL STUDIES from the last 15 years confirm that family is the primary source of community caregiving. Upwards of $50 \%$ to $80 \%$ of caregivers are spouses, $11 \%$ to $25 \%$ are daughters/daughters-in-law, and a smaller number consist of aging parents, female relatives, or friends. ${ }^{1-6}$ While these groups have been previously described in detail, little is known about how a caregiver's age impacts their experience and expectations. This article focuses on younger caregivers, a poorly understood and less-studied group.

Reports from the United Kingdom, Europe, Australia, and recently the United States have helped us identify this significant but mostly hidden group of caregivers, commonly defined as young people between the ages of 15 and 25 (although some were found to be as young as 8 years of age). ${ }^{7-14}$ The reports focus on young caregivers of individuals with various forms of chronic illness, such as mental health problems and dementia. Tasks ranged from shopping and cooking to medical care, showering, and toileting. Caregiving at the end of life lays claim to the physical, emotional, financial, existential, and social resources of those providing care. ${ }^{1,3,4,15,16}$ Unfortunately, our understanding of the needs of patients and their families remains limited, especially when their life-limiting illness is not cancer. ${ }^{17-20}$ Even less is known about particular subsets of caregivers, because of the lack of large, accessible datasets about caregivers of terminally ill patients.

We have previously demonstrated that the South Australian population-based Omnibus health survey can be used to define a cohort of people with terminal illness, as well as their caregivers. ${ }^{21}$ Our article seeks to remedy a gap in the literature using data from this large, annual health survey. The purpose of this current paper is to:

- Compare the sociodemographic features of the total population with those who reported they were active caregivers for the deceased individual;

\footnotetext{
${ }^{1}$ Palliative \& Supportive Service, School of Medicine, Flinders University, Adelaide, South Australia, Australia.

${ }^{2}$ Division of Medical Oncology, Department of Medicine, Duke University Medical Center, Durham, North Carolina.

Accepted May 12, 2010.
} 
Definition of palliative care used in all surveys:

"A palliative care service aims to comfort, not to cure, to relieve

pain and distress for people who are dying and to support

patients, families and friends in approaching death and coping

with grief."

\section{Survey}

1. In the past five years, has anyone close to you died of a terminal illness like cancer, motor neurone disease [amyotrophic lateral sclerosis] or emphysema? If yes, could you please say what that illness was?

2. How long ago did this person die?

3. What was your relationship to this person?

4. What was your most involved level of care for this person?*

5. Think back to when they were first diagnosed. Was the period after their diagnosis through to and including their death better or worse than you would have expected?*

6. Did this person who died of a terminal illness use a palliative care service?

\section{Survey}

New questions after question 4 (2001)

- For how long did you provide that care?

- Did you experience any financial burden as a result of this person's illness and death?*

Card for Question 3

What was your relationship to this person? (Interviewer: If more than one person, ask about the most recent person to die of a terminal illness.) (2001-2007)

Spouse/partner

Parent

Child

Sibling

Other relative

Friend

Other (specify)

Card for question 4

What was your most involved level of care for this person? (2001-07)

[Put responses on show card]

Day-to-day hands on care

Intermittent hands on care

Rare hands on care

Didn't provide any care but they were still close to me

FIG. 1. Survey questions. 


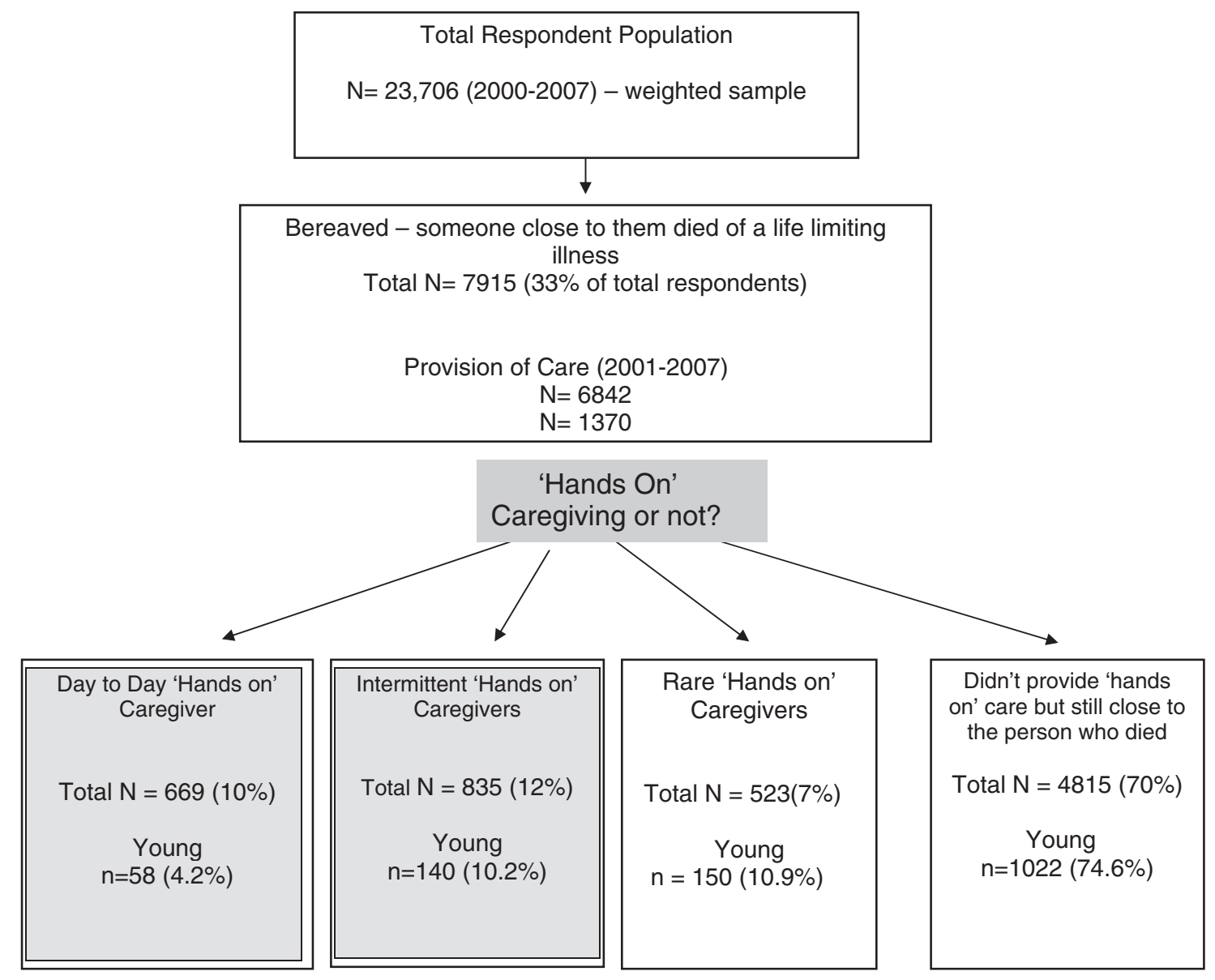

FIG. 2. Distribution of respondent population, bereaved and caregivers. Caregivers are subdivided into three caregiving categories, versus noncaregivers.

- Examine the sociodemographics and the role activities undertaken in caring for the deceased, dividing caregivers into three key age cohorts;

- Explore the caregiving experience among caregivers aged 15-29, with particular attention to examining their unique features.

\section{Methods}

The data for this survey were collected in the South Australian Health Omnibus Survey, a state government associated health survey conducted annually since 1991 with approximately 3000 residents each year. The full survey methodology has been detailed elsewhere. ${ }^{22}$

\section{Setting and subjects}

A total of 23,300 households across 7 years were selected for the survey, which was conducted annually during September to November in 2001 to 2007 using a randomized household selection procedure.

\section{Survey methodology}

A set of test questions was developed and reviewed annually by palliative care service volunteers and cognitively intact patients in the inpatient hospice. Palliative care questions were similar to those previously validated. ${ }^{21}$ Survey questions pertinent for the analyses presented here are in Figure 1.

Data collection. One face-to-face interview, by trained interviewers, was conducted per household with the person aged 15 or older who most recently had a birthday. Demographic information derived from the survey referred to the respondent and not the deceased.

Data analysis. The survey respondents were standardized against all South Australia for gender, 10-year age group, socioeconomic status, and region of residence in line with the 2001 Australian Census ${ }^{23}$ using direct standardization ${ }^{24}$ macros appropriate for combining multiple survey years obtained from the South Australian Department of Human Services. ${ }^{21,22}$ Each respondent was assigned a standardized weight and only weighted data were analyzed. There were no statistically significant differences between the years in response rate, demographics, recency of death, deaths due to cancer, the relationship between the respondent and deceased, or the care provided. We used three major age categories for analytical purposes in this paper. Our young cohort was therefore defined as those aged less than 30 years, extending by 5 years the more common international cohort (ages 15-25 years). This was considered a suitable cutoff point when viewed across the life continuum as most of those in their late teens and twenties are still approaching the high points of social and family responsibility (30-59 years). 
Table 1. Sociodemographic Characteristics: Total Population, Bereaved Who Identified as Involved in a Caring Role and Those Who Did Not

\begin{tabular}{|c|c|c|c|}
\hline \multirow[b]{2}{*}{ Characteristics } & \multirow[b]{2}{*}{$\begin{array}{l}\text { Total population } \\
\mathrm{N}=23,706\end{array}$} & \multicolumn{2}{|c|}{ Bereaved population $(\mathrm{n}=7915)$} \\
\hline & & $\begin{array}{l}\text { Self-identifed caring } \\
\quad \mathrm{N}=6842\end{array}$ & $\begin{array}{l}\text { Self-identifed noncaring } \\
\quad \mathrm{N}=1073\end{array}$ \\
\hline \multicolumn{4}{|l|}{ Gender } \\
\hline Female & 50.8 & 52.9 & 53.1 \\
\hline \multicolumn{4}{|l|}{ Age } \\
\hline $15-29$ & 24.3 & 20.0 & 21.9 \\
\hline $30-44$ & 27.0 & 26.7 & 25.8 \\
\hline $45-59$ & 24.5 & 28.7 & 28.0 \\
\hline $60-75$ & 15.7 & 16.8 & 16.5 \\
\hline \multirow{2}{*}{\multicolumn{4}{|c|}{ Marital }} \\
\hline & & & \\
\hline Married/de facto & 62.2 & $66.2^{\mathrm{b}}$ & 61.0 \\
\hline Separated/divorced & 8.2 & 8.5 & 9.5 \\
\hline Widowed & 6.0 & 6.4 & $9.0^{\mathrm{b}}$ \\
\hline Never married & 23.6 & 18.9 & 20.5 \\
\hline \multicolumn{4}{|l|}{ Area } \\
\hline Metropolitan & 70.9 & 67.8 & 69.1 \\
\hline Rural & 29.1 & 32.3 & 30.9 \\
\hline \multicolumn{4}{|l|}{ Country of birth } \\
\hline Australia & 78.6 & 78.6 & 78.3 \\
\hline Outside Australia & 21.4 & 21.4 & 21.7 \\
\hline \multicolumn{4}{|l|}{ Aboriginal \& Torres Strait Islander } \\
\hline Yes & 1.6 & 1.6 & 1.1 \\
\hline Education & & & a \\
\hline Still at school & 5.5 & 3.5 & 3.0 \\
\hline Left school at $<+15 \mathrm{yrs}$ & 14.0 & 13.8 & $18.8^{\mathrm{b}}$ \\
\hline Left school at $>15 \mathrm{yrs}$ & 30.7 & 30.2 & 29.8 \\
\hline Trade qualifications/apprenticeship & 13.7 & 15.0 & 14.7 \\
\hline Certificate/diploma & 21.5 & 23.5 & 21.0 \\
\hline Bachelor degree & 14.6 & 14.1 & 12.7 \\
\hline \multicolumn{4}{|l|}{ Employment\$ } \\
\hline Employed full-time & 37.4 & 38.5 & 37.0 \\
\hline Employed part-time or student & 25.3 & 24.6 & 22.3 \\
\hline Not employed/home duties/other & 37.3 & 36.9 & $40.7^{\mathrm{b}}$ \\
\hline \multicolumn{4}{|l|}{ Incomes } \\
\hline Up to $\$ 20,000$ & 18.5 & 18.6 & $24.6^{\mathrm{b}}$ \\
\hline$\$ 20,001-40,000$ & 18.8 & 18.3 & 18.6 \\
\hline$\$ 40,001-\$ 60,000$ & 17.2 & 17.8 & 19.2 \\
\hline$\$ 60,001$ or more & 30.4 & 32.4 & 24.4 \\
\hline Not stated & 15.2 & 12.9 & 13.2 \\
\hline \multicolumn{4}{|c|}{ Relationship to the person who died $N=5274$} \\
\hline Spouse/partner & 3.3 & 3.3 & 33.3 \\
\hline Parent/child & 14.4 & 14.4 & 0.0 \\
\hline Sibling & 5.2 & 5.2 & 0.0 \\
\hline Other relative & 42.7 & 42.7 & 66.7 \\
\hline Friend & 30.6 & 30.6 & 0.0 \\
\hline & 3.9 & 3.9 & 0.0 \\
\hline \multicolumn{4}{|l|}{ Relationship to the person who died } \\
\hline Close family (includes sibling) & 22.9 & 22.9 & 33.3 \\
\hline Other family & 42.7 & 42.7 & 66.7 \\
\hline Friend/other & 34.5 & 34.5 & 0.0 \\
\hline
\end{tabular}

${ }^{\mathrm{a}} p=<0.01$.

${ }^{\mathrm{b}}$ Adjusted residual $>2.0$.

Descriptive statistics were used to summarize respondent characteristics and responses. Relationships between categorical variables were tested using the $\chi^{2}$ test and $\chi^{2}$ test for trend. Two-tailed $p$ values were reported; statistical significance was assumed if $p<0.0500$. The SAS statistical package (SAS, Cary, NC) was used for analysis. $^{25}$

\section{Results}

\section{Sociodemographic characteristics} of all respondents and the bereaved

Detailed reports of the characteristics from the study have been published previously. ${ }^{21,26,27}$ In summary, 35\% of the population $(N=6842)$ indicated that someone "close to them 
Table 2. Sociodemographic Characteristics of Total Young Bereaved and Active Caregivers by Age Group (Numbers Are Percentages Unless Otherwise Indicated)

\begin{tabular}{|c|c|c|c|c|}
\hline \multirow[b]{2}{*}{ Characteristics } & \multirow[b]{2}{*}{$\begin{array}{l}\text { Young bereaved } \\
\mathrm{N}=1606\end{array}$} & \multicolumn{3}{|c|}{ "Hands-on" Caregiving population ${ }^{\mathrm{a}} \mathrm{N}=2027$} \\
\hline & & $\begin{array}{l}\text { Ages 15-29 } \\
\mathrm{N}=349\end{array}$ & $\begin{array}{c}\text { Ages } 30-59 \\
\mathrm{~N}=1208\end{array}$ & $\begin{array}{c}\text { Ages } \geq 60 \\
\mathrm{~N}=471\end{array}$ \\
\hline \multicolumn{4}{|l|}{ Gender } & $\mathrm{b}$ \\
\hline Female & 53.7 & 54.2 & 59.1 & 64.5 \\
\hline \multicolumn{5}{|l|}{ Marital } \\
\hline Married/de facto & 31.4 & 31.8 & 76.0 & 5.16 \\
\hline Separated/divorced & 1.8 & 1.1 & 11.1 & 5.3 \\
\hline Widowed & 0.2 & 0.0 & 3.7 & 41.6 \\
\hline Never married & 66.6 & 67.0 & 9.2 & 1.5 \\
\hline \multicolumn{5}{|l|}{ Area } \\
\hline Metropolitan & 69.6 & 65.4 & 68.8 & 67.8 \\
\hline Rural & 30.4 & 34.6 & 31.2 & 32.2 \\
\hline \multicolumn{5}{|l|}{ Country of birth } \\
\hline Australia & 71.2 & 94.6 & 77.1 & 64.9 \\
\hline Outside Australia & 28.8 & 5.4 & 22.9 & 35.1 \\
\hline \multicolumn{5}{|l|}{ Aboriginal \& Torres Strait Islander } \\
\hline \multirow{2}{*}{\multicolumn{5}{|c|}{ Education }} \\
\hline & & & & \\
\hline Still at school & 17.0 & 16.1 & 0.0 & 00.0 \\
\hline Left school at $<+15$ yrs & 2.9 & 3.0 & 6.6 & 37.7 \\
\hline Left school at $>15$ yrs & 36.4 & 30.5 & 31.6 & 23.7 \\
\hline Trade qualifications/apprenticeship & 12.1 & 16.1 & 14.5 & 11.4 \\
\hline Certificate/diploma & 19.4 & 20.1 & 29.7 & 19.7 \\
\hline Bachelor degree & 12.2 & 14.4 & 17.7 & 7.4 \\
\hline \multicolumn{5}{|l|}{ Employment $\S^{c}$} \\
\hline Employed full time & 41.5 & 38.1 & 47.4 & 04.2 \\
\hline Employed part-time or student & 43.9 & 46.5 & 29.8 & 8.4 \\
\hline Not employed/home duties/other & 14.6 & 15.4 & 22.8 & 87.4 \\
\hline \multicolumn{5}{|l|}{ Incomes } \\
\hline Up to $\$ 20,000$ & 8.5 & 08.3 & 10.3 & $48.8^{\mathrm{b}}$ \\
\hline$\$ 20,001-40,000$ & 13.7 & 12.4 & 18.8 & 21.7 \\
\hline$\$ 40,001-\$ 60,000$ & 20.8 & 22.1 & 18.7 & 9.8 \\
\hline$\$ 60,001$ or more & 32.9 & 29.9 & 40.6 & 7.4 \\
\hline \multirow{2}{*}{\multicolumn{5}{|c|}{$\begin{array}{l}\text { Not stated } \\
\text { Relationship to the person who died } N=5274\end{array}$}} \\
\hline & & & & \\
\hline Spouse/partner & 0.0 & 0.0 & 3.4 & 34.3 \\
\hline Parent/child & 4.8 & 12.4 & 40.0 & 16.5 \\
\hline Sibling & 0.6 & 1.7 & 3.6 & 8.5 \\
\hline Other relative & 65.2 & 64.7 & 31.1 & 16.9 \\
\hline Friend & 23.8 & 14.1 & 18.3 & 22.0 \\
\hline Other & 5.5 & 7.2 & 3.6 & 1.7 \\
\hline \multicolumn{5}{|l|}{ Relationship to the person who died } \\
\hline Close family (includes sibling) & 5.4 & 14.1 & 47.0 & 59.3 \\
\hline Other family & 65.2 & 64.7 & 31.1 & 16.9 \\
\hline Friend/Other & 29.4 & 21.3 & 21.9 & 23.7 \\
\hline
\end{tabular}

${ }^{\mathrm{a} C}$ Caregiving includes hands-on care provided daily, intermittent, or rarely.

$\mathrm{b}_{p}=<0.01$.

${ }^{\mathrm{N}}$ No figures for 2005.

had died of a terminal illness like cancer, motor neurone disease (a.k.a., amyotrophic lateral sclerosis or ALS], or emphysema" in the proceeding 5 years (Fig. 2). Among bereaved respondents, the sociodemographic profiles confirmed slightly more bereaved individuals were women, married, living in rural areas, and more highly educated (all $p<0.01$ ), when compared to respondents who did not report a death of one close to them. A slightly smaller proportion (29\%) identified they had some kind of care involvement. Of those who self-identified as not engaged at all in a caregiving role $(n=1073)$, most had a close relationship with the deceased being either a spouse/partner or an extended family member and were from across the age spectrum. They were significantly less likely to be married, have left school early, not be employed (although may be engaged in home duties) and on a very low income (Table 1 ). Overall, young active caregivers varied little in their sociodemographic composition when compared with young bereaved (Table 2).

\section{Caregivers}

The distinct caregiver subpopulations at the end of life comprised 502 (10\%) who provided daily care (5-7 days per 
Table 3. Profile of the Deceased Versus Active and Nonactive Caregivers and a Cohort of Those who Provided Their Active Care ay Age of Caregivers

\begin{tabular}{|c|c|c|c|c|c|c|c|}
\hline & \multirow{2}{*}{$\begin{array}{c}\text { Deceased } \\
\text { total } \\
\mathrm{N}=7915 \%\end{array}$} & \multirow{2}{*}{$\begin{array}{c}\text { Active } \\
\text { caregiver } \\
\mathrm{N}=1496\end{array}$} & \multirow{2}{*}{$\begin{array}{c}\text { Nonactive } \\
\text { caregiver } \\
\mathrm{N}=5295\end{array}$} & \multicolumn{4}{|c|}{ Age of active caregiver $\mathrm{n}=1505$} \\
\hline & & & & $\begin{array}{c}15-29 \\
\mathrm{~N}=199 \%\end{array}$ & $\begin{array}{c}30-59 \\
\mathrm{~N}=886 \%\end{array}$ & $\begin{array}{c}60+ \\
\mathrm{N}=420 \%\end{array}$ & $\mathrm{p}$ value \\
\hline Cancer & 79.1 & 78.6 & 78.5 & 78.9 & 79.7 & 79.3 & .964 \\
\hline Noncancer & 20.9 & 21.4 & 21.5 & 21.1 & 20.3 & 20.7 & \\
\hline \multicolumn{8}{|l|}{ Cause of death } \\
\hline Motor neurone disease & 2.9 & 2.5 & 3.1 & 4.0 & 2.2 & 2.1 & 0.304 \\
\hline Emphysema/other lung disease & 9.9 & 9.7 & 9.3 & 6.6 & 10.0 & 10.3 & 0.288 \\
\hline End-stage heart failure & 4.7 & 5.6 & 4.6 & 1.5 & 6.0 & 6.7 & 0.24 \\
\hline End-stage liver failure & 0.8 & 0.5 & 0.8 & 0.0 & 0.7 & 0.5 & $0.488^{\mathrm{b}}$ \\
\hline End-stage kidney failure & 1.0 & 1.1 & 0.8 & .5 & 0.8 & 1.9 & $0.133^{b}$ \\
\hline $\mathrm{HIV} / \mathrm{AIDS}$ & 0.4 & 0.3 & 0.4 & 0.0 & 0.5 & 0.0 & $0.274^{b}$ \\
\hline Other & 4.6 & 5.3 & 4.2 & 8.5 & 5.3 & 3.6 & 0.035 \\
\hline Don't know & 0.8 & 0.7 & 0.8 & 1.0 & 0.7 & 0.5 & $0.747^{\mathrm{b}}$ \\
\hline \multicolumn{3}{|l|}{ Time From death } & c & & & & \\
\hline 0-6 months & 23.3 & 18.3 & 24.8 & 17.1 & 19.6 & 16.3 & \multirow[t]{7}{*}{$<0.001$} \\
\hline 7-12 months & 17.3 & 15.7 & 17.7 & 20.7 & 15.4 & 14.1 & \\
\hline 13-18 months & 5.7 & 6.8 & 5.4 & 5.7 & 7.2 & 6.2 & \\
\hline 19-24 months & 15.9 & 16.2 & 15.8 & 29.0 & 14.4 & 14.1 & \\
\hline 25-36 months & 16.9 & 18.7 & 16.4 & 14.0 & 17.9 & 22.2 & \\
\hline 37-48 months & 12.1 & 14.6 & 11.4 & 11.4 & 14.4 & 16.5 & \\
\hline 49-60 months & 8.8 & 9.8 & 8.5 & 2.1 & 11.2 & 10.5 & \\
\hline \multicolumn{3}{|l|}{ Age of deceased $(n=622)$} & \multicolumn{2}{|l|}{ c } & & & \multirow{7}{*}{$<0.001$} \\
\hline$<40(n=31)$ & 5.5 & 5.0 & 5.7 & 10.3 & 4.9 & 2.5 & \\
\hline $40-49(n=50)$ & 10.0 & 8.1 & 10.6 & 23.1 & 6.7 & 3.8 & \\
\hline $50-59(n=87)$ & 18.1 & 14.0 & 11.4 & 14.2 & 14.7 & 12.1 & \\
\hline $60-59(n=107)$ & 21.1 & 17.3 & 22.2 & 11.5 & 17.3 & 19.7 & \\
\hline $70-79(n=205)$ & 26.5 & 32.9 & 24.6 & 24.4 & 36.2 & 29.3 & \\
\hline $80+(n=142)$ & 18.7 & 22.7 & 17.6 & 16.7 & 20.2 & 32.5 & \\
\hline \multicolumn{3}{|l|}{ Place of death $(n=414)$} & c & & & & \multirow{5}{*}{0.307} \\
\hline Home $(n=90)$ & 19.4 & 21.1 & 18.9 & 29.5 & 19.6 & 20.6 & \\
\hline Hospital $(n=221)$ & 59.5 & 53.1 & 61.3 & 44.9 & 56.3 & 49.7 & \\
\hline Hospice $(n=65)$ & 13.4 & 15.3 & 12.9 & 15.4 & 14.7 & 16.1 & \\
\hline RACF $(n=38)$ & 7.7 & 10.6 & 6.9 & 10.3 & 9.3 & 13.5 & \\
\hline \multicolumn{2}{|l|}{ SPCS Use $(n=1431)$} & & c & & & & \multirow[t]{3}{*}{0.372} \\
\hline Yes & 57.4 & 62.7 & 56.9 & 58.5 & 62.6 & 64.7 & \\
\hline No & 42.6 & 37.3 & 44.0 & 41.5 & 37.4 & 35.3 & \\
\hline
\end{tabular}

${ }^{\mathrm{a}}$ Active care $=$ hands-on daily and intermittent caregiver.

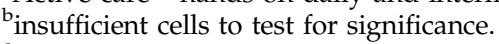

${ }^{c} p=<0.001$.

HIV/AIDS, human immunodeficiency virus/acquired immune deficiency syndrome; RACF, Residential Aged Care Facility; SPCS, Specialist Palliative Care Service as integrated tertiary and primary care services.

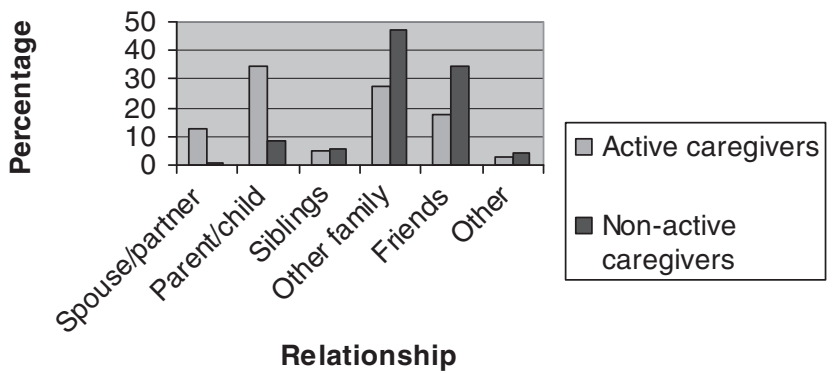

FIG. 3. Relationship of the deceased by caregiving role. week], 619 (12\%) provided intermittent care (2-4 days per week], $425(8 \%)$ provided rare care, and a large group were non-caregiving bereaved individuals 3756 (70\%). Among the young cohort, however, these proportions differed with young people less likely to be engaged in daily hands-on care, more likely to undertake caregiving activities on a rarer basis and slightly higher levels reporting they had no active caregiving involvement (Fig. 2).

The sociodemographic features of these active caregivers aged 15-29 years identified some important differences when compared to the other age cohorts (Table 2). Forty-six percent were males, most were not married $(69 \%)$, almost all were Australia-born (95\%), and 16\% were still at school. Improved Australian educational standards are reflected in the higher levels of qualifications of those under 60. Most young people 
Table 4. Profile of Experiences of Active Caregiving a by Age of the Caregiver

\begin{tabular}{|c|c|c|c|c|c|c|c|c|c|}
\hline \multirow[b]{2}{*}{ Characteristics } & \multirow[b]{2}{*}{$\begin{array}{c}\text { Total } \\
\mathrm{N}=1504\end{array}$} & \multicolumn{3}{|c|}{ Day to day $\mathrm{N}=669$} & \multirow[b]{2}{*}{$\mathrm{p}$ value } & \multicolumn{3}{|c|}{ Intermittent $\mathrm{N}=835$} & \multirow[b]{2}{*}{$\mathrm{p}$ value } \\
\hline & & $\begin{array}{l}15-29 \\
\mathrm{n}=54\end{array}$ & $\begin{array}{c}30-60 \\
\mathrm{n}=360\end{array}$ & $\begin{array}{c}60+ \\
\mathrm{n}=241\end{array}$ & & $\begin{array}{c}15-29 \\
\mathrm{n}=140\end{array}$ & $\begin{array}{c}30-60 \\
\mathrm{n}=521\end{array}$ & $\mathrm{~N}=174$ & \\
\hline \multicolumn{10}{|l|}{ Length of care provided $(n=1360)$} \\
\hline $0-3$ months & 27.0 & 35.7 & 34.2 & 21.8 & \multirow{4}{*}{0.001} & 26.9 & 24.7 & 26.2 & \multirow[t]{4}{*}{0.08} \\
\hline 4-6 months & 19.7 & 21.4 & 20.3 & 11.2 & & 33.3 & 19.1 & 20.5 & \\
\hline 7-12 months & 16.6 & 3.6 & 13.5 & 18.8 & & 15.1 & 18.5 & 18 & \\
\hline$>12$ months & 36.7 & 39.3 & 32.1 & 48.2 & & 24.7 & 37.6 & 35.2 & \\
\hline \multicolumn{10}{|l|}{ SPCS use $(n=6640)$} \\
\hline Yes & 62.7 & 55.6 & 61.9 & 64.3 & \multirow[t]{2}{*}{0.477} & 60.2 & 63.0 & 65.2 & \multirow[t]{2}{*}{0.689} \\
\hline No & 37.3 & 44.4 & 38.1 & 35.7 & & 39.8 & 37.0 & 34.8 & \\
\hline \multicolumn{10}{|l|}{ Expectations of death $(n=5928)$} \\
\hline Much better than expected & 15.1 & 8.8 & 20.1 & 9.4 & \multirow[t]{4}{*}{0.003} & 19.2 & 13.0 & 17.3 & \multirow[t]{4}{*}{0.06} \\
\hline As expected & 31.0 & 26.3 & 21.7 & 29.1 & & 26.2 & 38.0 & 38.7 & \\
\hline Worse or much worse than expected & 45.0 & 54.4 & 50.6 & 47.3 & & 42.3 & 41.9 & 37.3 & \\
\hline Didn't know what to expect & 8.9 & 10.5 & 7.5 & 14.1 & & 12.3 & 7.1 & 6.7 & \\
\hline \multicolumn{10}{|l|}{ Sought help to deal with grief $(n=2745)$} \\
\hline Yes & 38.2 & 50.0 & 43.2 & 42.4 & \multirow[t]{2}{*}{0.850} & 51.6 & 33.1 & 22.2 & \multirow[t]{2}{*}{0.002} \\
\hline No, not needed with & 61.8 & 50.0 & 56.8 & 57.6 & & 48.4 & 66.9 & 77.8 & \\
\hline
\end{tabular}

${ }^{a}$ Active caregivers comprise those providing daily or intermittent hands-on care.

SPCS, Specialist Palliative Care Service as integrated tertiary and primary care services.

For bold values, $p<0.05$.

involved in active caregiving were also working (85\%), including $38 \%$ employed full-time. It is likely that income was underreported as one quarter would not declare it and as a group they were receiving high incomes with $33 \%$ receiving $\$ \mathrm{~A} 60,000$ or more per annum (Table 2).

\section{Caregivers and family}

Young active caregivers were more likely to be a close family member compared to younger bereaved. However, compared to middle-aged and older caregivers, younger caregivers were much more likely to be related to the deceased in more distant ways (Table 2). Interestingly, young people were almost also as likely to care for friends and others as did those over 30. Over half of young caregivers indicated that the deceased had been aged over 60 and $17 \%$ said they were 80 and older (Table 3 ). While the proportions of the deceased with cancer were the same across the age distribution of the caregivers, two other diseases showed significant differences. Young people were significantly less likely to be involved in the active care of a person with end stage heart failure and significantly more likely to have been involved with persons who had a cluster of "other" diseases (Table 3).

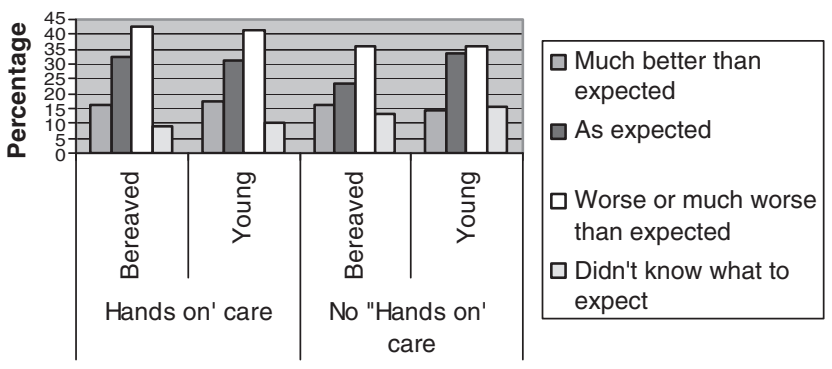

FIG. 4. Bereaved perception of illness experience of caregivers and noncaregivers.
Significantly high numbers of these young people $(80 \%)$ recorded it was less than 2 years since the death of the deceased compared with those people over $30(50 \%-57 \%)$. No major differences by age were reported in access to palliative care services (Table 3 ).

\section{How much did the active caregiver profile differ from the inactive?}

There were no significant statistical difference for causes of death (Table 3). However, time from death, age of deceased, and place of death did show significant differences: in particular those not engaged in active care reported higher numbers died in hospital $(61.3 \% p \leq 0.001)$ compared to those who were active caregivers who reported that only $53 \%$ died there (Table 3). There were also significant differences in the use of palliative care services with active caregivers much more likely to use this resource $(63 \%)$ compared to nonactive caregivers (57\%; Table 3). Predictably, the relationship to the deceased was a major difference, with significantly higher proportions of active caregivers related to the deceased as spouse, parent or child while nonactive caregivers were much more likely to be extended family members or friends (Fig. 3).

\section{Caregiver experience}

In general, more than half of younger caregivers were significantly more likely to be engaged in hands-on care for less than 6 months in contrast to those aged 60 who most provided care for longer than 6 months (Table 4). A substantial proportion $(39 \%)$ provided this intensive care, that is, on a daily hands-on basis, for more than 12 months.

Overall, $63 \%$ of those undertaking active caregiving indicated Specialist Palliative Care Services were available to them and this proportion was not significantly different among the three aged cohorts.

Respondents were asked to indicate in what way the actual experience of death matched their expectations. Among the 
Table 5. Perception of Caregiving by Time from Death of Deceased for Those Aged Under Thirty and Those Over Sixty

\begin{tabular}{|c|c|c|c|c|c|c|c|c|c|c|}
\hline \multirow{3}{*}{ Time from death } & \multicolumn{10}{|c|}{ Expectations } \\
\hline & \multicolumn{2}{|c|}{$\begin{array}{l}\text { Much better } \\
\text { than expected }\end{array}$} & \multicolumn{2}{|c|}{ As expected } & \multicolumn{2}{|c|}{$\begin{array}{c}\text { Worse or much } \\
\text { worse than expected }\end{array}$} & \multicolumn{2}{|c|}{$\begin{array}{l}\text { Didn't know } \\
\text { what to expect }\end{array}$} & \multicolumn{2}{|c|}{ Total } \\
\hline & $<30$ & $>60$ & $<30$ & $>60$ & $<30$ & $>60$ & $<30$ & $>60$ & $<30$ & $>60$ \\
\hline 0-12 months & $45.1^{\mathrm{a}}$ & 46.3 & 33.1 & 42.6 & $42.3^{\mathrm{a}}$ & 39.8 & 31.7 & 32.8 & 38.2 & 40.8 \\
\hline 13-24 months & 20.7 & 18.2 & 27.9 & 20.5 & 21.9 & 23.8 & $32.9^{\mathrm{a}}$ & 26.6 & 25.1 & 22.3 \\
\hline 25-36 months & 16.8 & 16.4 & 18.3 & 18.1 & 16.1 & 16.8 & 17.1 & 16.9 & 17.1 & 17.2 \\
\hline $\begin{array}{l}37-60 \text { months } \\
\text { Total } 100.0\end{array}$ & 17.4 & 19.2 & 20.7 & 18.8 & 19.9 & 19.6 & 18.3 & 23.7 & 19.5 & 19.8 \\
\hline
\end{tabular}

${ }^{\text {a }}$ Adjusted residual $>2.0$.

$p=0.026$ for those aged $<30$ years.

No significant difference for those aged $<60$ years.

bereaved who provided no hands-on care, both in general and the young in particular, reported remarkably similar profiles (Fig. 4). Approximately 15\% thought the experience better than expected, just over a third each thought it was "as expected" or "worse or much worse than expected" and approximately $14 \%$ did not know what to expect.

However, for those who did provide hands-on care, the profile was very different for age cohorts. Very few of both the young and the old who provided hands-on care reported it was better than expected ( $9 \%$ ), although $20 \%$ of those aged 30-59 found it to be so. Instead, half of all those undertaking hands-on care reported it was worse or much worse than expected. This negative perception was lower among all those providing care on an intermittent basis. Further among this young cohort undertaking intermittent care, one fifth reported the experience was "much better than expected" and a quarter that it was "as expected" (Table 4). Did time from death influence perception? We explored the younger and older cohorts (Table 5) and found that both populations report intense impressions in the first year. Among the younger cohort, they were equally as likely to report the experience was better then expected as they were to report it was worse or much worse.

Did length of care impact on perceptions? Young caregivers who provided care for less than 12 months were twice as likely to indicate the experience was negative as those who undertook long-term care (Fig. 5). Interestingly, among those who undertook longer care, a substantially higher number $(44 \%)$ reported it was better than expected. It was not possible to test for significance as numbers were too small.

Much higher proportions of all three age groups providing daily hands-on care indicated they needed help with their



FIG. 5. Comparison of all caregivers and young caregivers perception of illness experience $\times$ length of care undertaken. grief. Among the young, high numbers (52\%) still reported a need for help (Table 4).

\section{Caregivers experience when deceased had noncancer}

When the deceased had a noncancer condition, levels of care did not differ significantly from those with a cancer condition. But young caregivers were significantly more likely to undertake a longer period of caregiving when the deceased had a noncancer condition, with over half (53\%) indicating they provided care for more than 12 months in comparison with $40 \%$ who indicated they assisted for 3 months or less when the deceased had died from cancer (Table 6). Furthermore, the use of palliative care services differed significantly with $56 \%$ of the young reporting such services were not used when the deceased had a noncancer condition.

\section{Discussion}

This study, using a population-based sample and a caregiver concept based on role activity rather than family relationship, identified a surprisingly high proportion of young people (ages 15-29) contributing hands-on care (14.4\%) to patients at the end of life. Almost as many young males as females participate in active caregiving (men represent $46 \%$ ); most provide care while also being employed, including $38 \%$ who work full-time. Young caregivers frequently report that the experience was worse than expected ( $42 \%$ of intermittent and $54 \%$ of day-to-day caregivers), and recognized a need for assistance with grief during the bereavement period.

Families provided the backbone of caregiving with $80 \%$ of active care being undertaken by them, confirming as $\mathrm{Ell}^{28}$ has stressed, that the family connection is the most important aspect when serious illness is involved. A U.S. study of a small sample of children and grandchildren providing the major source of support to an older relative indicated they did so because of both filial duty and a general willingness to help the primary caregiver. ${ }^{29}$

Our data identified almost as many young males were actively caring as females; this is different from past generations when caregiving responsibilities were predominantly the purview of women. Secondary analysis of U.K. data from the 1990 's confirmed the trend of increasing numbers of men 
Table 6. Profile of Caregiving $\times$ Age $\times$ Cancer Versus Noncancer Life-Limiting Illness

\begin{tabular}{|c|c|c|c|c|}
\hline \multirow[b]{2}{*}{ Characteristics of caregiving } & \multirow[b]{2}{*}{$\begin{array}{l}\text { Total young aged } \\
\quad \mathrm{N}=5772\end{array}$} & \multicolumn{2}{|c|}{ 15-29 Age } & \multirow[b]{2}{*}{$\mathrm{p}$ value } \\
\hline & & $\begin{array}{c}\text { Cancer } \\
\mathrm{N}=6180\end{array}$ & $\begin{array}{l}\text { Noncancer } \\
\mathrm{N}=1701\end{array}$ & \\
\hline \multicolumn{5}{|l|}{ Any care } \\
\hline Yes $(n=1,362)$ & 25.4 & 24.9 & 27.7 & 0.340 \\
\hline \multicolumn{5}{|l|}{ Level of care provided $(n=1,362)$} \\
\hline Day-to-day hands on $(n=58)$ & 4.3 & 4.2 & 4.7 & \\
\hline Intermittent hands-on care $(n=139)$ & 10.2 & 9.9 & 11.3 & 0.818 \\
\hline Rare hands-on care $(n=149)$ & 10.9 & 10.8 & 11.7 & \\
\hline Didn't provide care but still close $(n=1016)$ & 74.6 & 75.1 & 72.3 & \\
\hline Length of care $(n=226)$ & & & & 0.022 \\
\hline$<1$ year & 62.4 & 65.9 & 46.3 & \\
\hline$>1$ year & 37.6 & 34.1 & 53.7 & \\
\hline \multicolumn{5}{|l|}{ Length of care provided $(n=226)$} \\
\hline $0-3$ months & 39.8 & 44.6 & 19.0 & \\
\hline 4-6 months & 24.8 & 25.5 & 21.4 & $<0.0001$ \\
\hline 7-12 months & 11.9 & 13.0 & 7.1 & \\
\hline$>12$ months & 23.5 & 16.8 & 52.4 & \\
\hline \multicolumn{5}{|l|}{$\operatorname{SPCS}^{\mathrm{a}}$ use $(n=1,319)$} \\
\hline Yes $(n=991)$ & 54.6 & 57.3 & 43.7 & $<0.000$ \\
\hline No $(n=328)$ & 45.4 & 42.7 & 56.3 & \\
\hline
\end{tabular}

aSPCS, Specialist Palliative Care Services provided as integrated tertiary and primary care services.

providing informal care to their spouse or partner. ${ }^{30}$ Our data lead us to pose the question, will this trend continue as the young cohort move to middle age? Men are participating more in many caring activities including raising children, teaching, and nursing. As caregiving takes on new positive meaning for men ${ }^{31,32}$ it is possible that we will see greater numbers of male caregivers across the whole age spectrum.

Small-scale studies have identified financial hardship as a major problem for young caregivers. ${ }^{33,34}$ Our study confirmed that most were employed, half of them were receiving high incomes and less than $10 \%$ earned under $\$ 20,000$ per annum. This profile suggests there may be two distinctive groups of young caregivers in the community: those providing long-term care to parents with chronic illness and those we have identified, who may be assisting the family in caring, for a shorter time, for an older or elderly relative with a terminal illness.

Evaluating the impact of serious illness we were able to explore, in a preliminary way, perceptions around the dying experience for the bereaved, some of whom were active caregivers. One third of bereaved, of all ages, found the experience worse than expected. We could not identify from this data, for how many this was their first death experience of a lingering disease. However, another third also reported it was "as they expected." We note that between $13 \%$ and $15 \%$ had no idea what to expect. These figures offer a further line of research.

Of some concern was the fact that so many of those involved in hands-on care found it to be worse or much worse than expected and this included the young. While acknowledging that many were closely related to the deceased and reported high grief levels, nonetheless the clinical question could be asked, were they given adequate preparation and support by health professionals? It might be that those engaged in longer caring, 1 to 2 years, were more likely to meet with and obtain information and support and thus indicate that it was much better than expected.
Half of the young caregivers in this study requested help with their grief during the bereavement period. Whether "active caring" was the precipitous factor or whether the loss of a close family member was the proximate cause of this increased need for assistance is not clear.

U.K. qualitative researchers have attempted to ascertain the far-reaching consequences for young caregivers of caring for the seriously ill. ${ }^{7,8,12}$ We know that young caregivers continue to remain invisible to health professionals and teachers. $7,8,33-37$ A chart review of 3479 patients who died in a hospice and home health care program noted that the psychosocial assessment form providing space to identify the primary caregiver, did not enumerate children in the genogram of the family system. ${ }^{38}$ A recent Australian report identified a range of family, service and system issues that impede young caregivers' access to services. ${ }^{39}$ A whole of family approach that acknowledges the complexity of social and economic forces is recommended.

\section{Limitations to the study: Sample}

People who live in remote, as distinct from rural, South Australia, those without caregivers, and some people with culturally and linguistically diverse backgrounds were not represented in the data. All results were based upon the recall of the respondent, which is a validated approach. ${ }^{40} \mathrm{Re}-$ spondents may not reliably know whether the deceased used a palliative care service or the place of death, especially when the respondent was not providing frequent care.

Concentration of analyses on those who knew the answers to both questions improved reliability of results. Other limitations were outlined previously. ${ }^{21}$ The other challenge in understanding characteristics of caregivers' demographics is that respondents are providing current status in responses. For example, marital status is current status not the respondent's status when providing care so that widowed people may (or may not) have been spousal caregivers. 


\section{Conclusion}

Young caregivers, who are to date almost invisible in the cancer research literature, can be integral to end-of-life care. Large population-based studies are sufficiently powered to facilitate the identification of important sub-groups of caregivers. Our data raise concern that the cohort of young caregivers may have more negative experiences with caregiving, and more difficulty with grief thereafter, or at least a heightened willingness to ask for help. Designing further clinical studies of sufficient size to capture these differing experiences will improve the quality of our insights into endof-life caregiving, allowing us to better tailor interventions to subsets of the caregiver population and target the special concerns of young caregivers.

\section{Acknowledgments}

Preliminary results presented at the 2008 International Psycho-Oncology Conference in Madrid.

This article presents original research of the authors. All authors provided substantial contributions to the study planning, data analysis, and manuscript production.

Direct costs of this study were provided through discretionary research funds held by Southern Adelaide Palliative Services, Daw Park, South Australia, Australia with supplemental funding from the Daw House Hospice Foundation, Daw Park, South Australia, Australia (AU\$22,500).

\section{Author Disclosure Statement}

No competing financial interests exist.

\section{References}

1. Kurtz ME, Kurtz JC, Given CW, Given B: Relationship of caregiver reactions and depression to cancer patients' symptoms, functional states and depression-A longitudinal view. Soc Sci Med 1995;40:837-846.

2. Howe AL, Schofield H, Herrman H: Caregiving: A common or uncommon experience? Soc Sci Med 1997;45:1017-1029.

3. Nijboer C, Tempelaar R, Sanderman R, Triemstra M, Spruijt RJ, van den Bos GA: Cancer and caregiving: The impact on the caregiver's health. Psychooncology 1998;7:3-13.

4. Emanual EJ, Fairclough D L, Slutsman J, Hillel A deWitt B, Emanual LL: Assistance from family members, friends, paid care givers, and volunteers in the care of terminally ill patients. N Engl J Med 1999;341:956-963.

5. Burns CM, Smith WT, Dixon T, Craft PS, Broom D: Caregiver knowledge of treatment intent in a longitudinal study of patients with advanced cancer [see editorial 617-619]. Support Care Cancer 2003;11:629-637.

6. Aoun SM, Kristjanson LJ, Currow DC, Hudson PL: Caregiving for the terminally ill: At what cost? $\underline{\text { Palliat Med }}$ 2005;19:551-555.

7. Aldridge J, Beckers S: Children Who Care: Inside the World of Young Caregivers. Loughborough: Loughborough University Young Carers Research Group, 1993.

8. Aldridge J, Becker S: Befriending Young Carers. A Pilot Study. Loughborough: Loughborough University Young Carers Research Group, 1996.

9. NATSEM (National Centre for Social and Economic Modelling): Who's going to care? Informal care and an ageing population. Report prepared for Carers Australia. 2004.
10. National Alliance for Caregivers. Young Caregivers in the US. Report of Findings. National Alliance for Caregivers and The United Hospital Fund, 2005.

11. Becker S: Young Carers in Europe: An explanatory Crossnational Study in Britain, France, Sweden \& Germany. Loughborough: Loughborough University Young Carers Research Group, 1995.

12. Doran T, Drever F, Whitehead M: Health of young and elderly informal carers: Analysis of UK census data BMJ 2003;327:1388.

13. Aldridge J, Becker S: Children as carers: The impact of parental illness and disability on children's caring roles. I Fam Ther 1999;21:303-320.

14. Disability, Ageing and Carers Australia: Caring in the Community. Report 4436.0. Canberra: Australian Bureau of Statistics, 1998.

15. Schulz R, Visintainer P, Williamson GM: Psychiatric and physical morbidity effects of caregiving. I Gerontol 1990;45: 181-191.

16. Schulz R, Beach SR: Caregiving as a risk factor for mortality. The Caregiver Health Effects Study. JAMA 1999;282:22152219.

17. Levenson JW, McCarthy EP, Lynn J, Davis RB, Phillips RS: The last six months of life for patients with congestive heart failure. J Am Geriatr Soc 2000;48(5 Suppl):S101-109.

18. Tranmere JE, Heyland D, Dudgeon D, Groll D, SquiresGraham M, Coulson K: Measuring the symptom experience of seriously ill cancer and non-cancer hospitalized patients near the end of life with the memrial symptom assessment scale. I Pain Symptom Manage 2003;25:420-429.

19. Weisbord SD, Carmody SS, Bruns FJ, Rotondi AJ, Cohen LM, Zeidel ML, Arnold RM: Symptom burden, quality of life, advance care planning and the potential value of palliative care in severely ill haemodialysis patients. Nephrol Dial Transplant 2003;18:1345-1352.

20. Solano, JP, Gomes B, Higginson IJ: A comparison of symptom prevalence in far advanced cancer, AIDS, heart disease, chronic obstructive pulmonary disease and renal disease. I Pain Symptom Manage 2006;31:58-69.

21. Currow DC, Abernethy AP, Fazekas BS: Specialist palliative care needs of whole populations: A feasibility study using a novel approach. Palliat Med 2004;18:239-247.

22. Wilson DH, Wakefield M, Taylor AW: The South Australian Health Omnibus Survey. Health Promotion J Aust 1992;2: $47-49$.

23. 2001 Census Basic Community Profile and Snapshot-South Australia, Australian Bureau of Statistics, 2004.

24. Curtin L, Klein R: Direct standardization (age-adjusted death rates), Statistical Notes, no 6. Hyattsville, MD: National Center for Health Statistics, 1995.

25. SAS: The SAS System, release 9.1, Cary, NC.

26. Abernethy AP, Currow DC, Fazekas BS, Luszcz MA, Wheeler JL, Kuchibhatla M: Specialized palliative care services are associated with improved short- and long-term caregiver outcomes. Support Care Cancer 2008;16:585-597.

27. Abernethy AP, Burns CM, Wheeler J, Currow DC: Defining distinct caregiver sub-populations by intensity of end-of-life care provided. Palliat Med 2009;23:66-79.

28. Ell K: Social networks, social support and coping with serious illness: The family connection, Soc Sci Med 1996;42:173-183.

29. Dellman-Jenkins M, Blankemeyer M, Pinkard O: Young adult children and grandchildren in primary caregiver froles to older relatives and their service needs. Family Relat 2000;49:177-186. 
30. Hirst M: Transitions to informal care in Great Britain during the 1990s. J Epidemiol Commun Health 2002;56:579-587.

31. Harris PB: Listening to caregiving sons: Misunderstood realities. Gerontologist 1998;38:342-352.

32. Campbell LD, Carroll MP: The incomplete revolution. Men Masc 2007;9:491-508.

33. Carers Australia: Young carers research project: Background papers. Commonwealth Department of Family and Community Services. 2002.

34. Cree VE: Worries and problems of young carers: Issues for mental health. Child Fam Soc Work 2003;8:301-209.

35. Lackey NR, Gates MF: Adults recollections of their experiences of young caregivers of family members with chronic physical illnesses. J Adv Nurs 2001;34:320-328.

36. Nostlinger $C$, Jonckheer $T$, de Belder $E$, van Wijngaerden $E$, Wylock C, Pelgrom J, Colebunders R: Families affected by HIV: Parents' and children's characteristics and disclosure to the children. AIDS Care 2004;16:641-648.

37. Schrag A, Hovris A, Morley D, Quinn N, Jahanshahi M: Caregiver-burden in parkinson's disease is closely associated with psychiatric symptoms, falls, and disability. Parkinsonism Relat Disord 2006;12:35-41.
38. Siskowski C, Diaz N, Connors L, Neal MA: Recognition and assessment of caregiving youth in hospice and home healthcare. Home Health Care Nurs 2007;25:433-438.

39. Moore T, McArthur M: We're all in it together: Supporting young carers and their families in Australia. Health Soc Care Commun 2008;15:561-568.

40. McPherson CJ, Addington-Hall JM: Judging the quality of care at the end of life: Can proxies provide reliable information? Soc Sci Med 2003;56:95-109.

Address correspondence to: Catherine Mary Burns, B.A., BSWSA, MPhil, Ph.D. Palliative E Supportive Service, School of Medicine

Flinders University

Bedford Park

Adelaide

South Australia

Australia 5041

E-mail: Catherine.Burns@flinders.edu.au 
